\title{
The Linear City: illustrating the logic of spatial equilibrium
}

\author{
Michael Batty ${ }^{*}$ (1)
}

\begin{abstract}
Linear cities where activity is spread out along a transportation line, aim to offer the highest levels of accessibility to their adjacent populations as well as to the countryside. These city forms are popular amongst architects and planners in envisioning ideal cities but they are difficult to implement as they involve strict controls on development which often ignore human behaviour associated with where we locate and how we move. We briefly explore the history of these ideas, noting the latest proposal to build a $170 \mathrm{~km}$ city called Neom in north west Saudi Arabia, a plan that has attracted considerable criticism for its apparent ignorance of how actual cities grow and evolve. We use a standard model of human mobility based on gravitational principles to define a set of equilibrium conditions that illustrate how a theoretical city on a line would, without any controls, successively adapt to such a new equilibrium. First, we represent the city on a line, showing how its population moves to an equilibrium along the line, and then we generalise this to a bigger two-dimensional space where the original line cutting across the grid evolves as populations maximise their accessibility over the entire space. In this two-dimensional world, we simulate different forms that reflect a balance of centralising versus decentralising forces, showing the power of such equilibria in destroying any idealised form. This approach informs our thinking about how far idealised future cities can depart from formal plans of the kind that the linear city imposes.
\end{abstract}

Keywords: Linear cities, Neom, Gravitational interaction, Accessibility on a line, Spatial equilibrium, Developments on a grid

Cities that capture the ideas of visionary architects and planners often bear little resemblance to the way most cities grow and evolve. Lucio Costa generated his plan for the new capital of Brasilia by drawing a 'cross' on the legendary 'back of an envelope.' He proceeded to elaborate it into the shape of an aeroplane (or bird) which then became the master plan around which everything else revolved as the city was rapidly constructed from the late 1950 s on. If you examine this sketch, you are immediately struck by how unrealistic it is and on thinking about how people actually behave in cities, it looks as though this shape is completely incompatible with what we know about the form and function of most contemporary cities.

\footnotetext{
*Correspondence: m.batty@ucl.ac.uk

Centre for Advanced Spatial Analysis, University College London, 90 Tottenham Court Road, London W1T 4TJ, UK
}

Cities tend to grow around some centre in concentric zones of land use sorted according to their ability to pay rent, linked to this core using well-defined radial routes converging on the centre. Since Brasilia was founded, the population and its various activities attracted to the city have located more or less anywhere they can around the 'cross', generally ignoring the dominant form of the masterplan which consists of the two wings of the plane or bird that Costa used to define its basic form. We show the plan and its origins in Fig. 1.

In the 70 years that has elapsed since the plan was begun, the city has evolved to an entirely new equilibrium more like a contemporary city of polycentric form. Costa's masterplan is still enshrined in the two wings but most of the city resembles a much more naturally growing organic form (Banerji, 2012). If this lesson in architectural determinism means anything at all, it suggests

\section{블 Springer}

(C) The Author(s) 2022. Open Access This article is licensed under a Creative Commons Attribution 4.0 International License, which permits use, sharing, adaptation, distribution and reproduction in any medium or format, as long as you give appropriate credit to the original author(s) and the source, provide a link to the Creative Commons licence, and indicate if changes were made. The images or other third party material in this article are included in the article's Creative Commons licence, unless indicated otherwise in a credit line to the material. If material is not included in the article's Creative Commons licence and your intended use is not permitted by statutory regulation or exceeds the permitted use, you will need to obtain permission directly from the copyright holder. To view a copy of this licence, visit http://creativecommons.org/licenses/by/4.0/. 

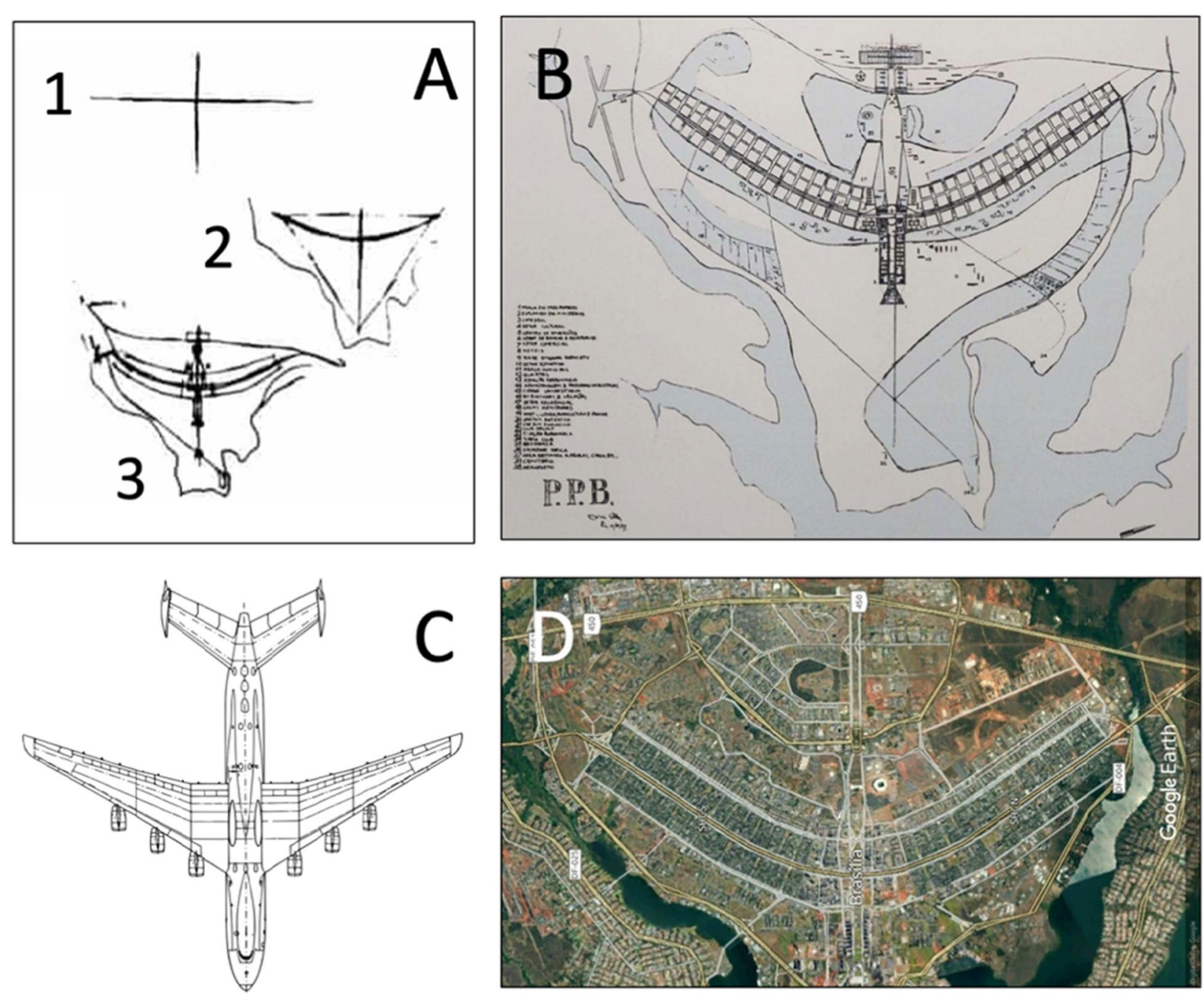

Fig. 1 Brasilia. A) Lucio Costa's Original Sketches, B) his first Master Plan, and C) Configured Geometrically as a Plane or Bird and D) A Satellite View of the Original Wing Structure, Today, from Google Earth

that cities have a natural equilibrium which will always assert itself once the population is able to make its own locational decisions over where they might live and work and how they might interact with one another. You might think that experiences like this convince us that ideal cities simply fashioned on regular geometric forms that bear no relationship to the way the city might function would have been abandoned long ago. But far from it. In 2020, the Crown Prince of Saudi Arabia proposed a new city for a million people who are to be spread out along a dead straight line $170 \mathrm{~km}$ in length. ${ }^{1}$ It will be a city where everything one needs will be within five minutes' walk, it will be no more than half a kilometre in width, and it

\footnotetext{
${ }^{1}$ See video of the plan for Neom https://www.youtube.com/watch?v=41sgR P0G6y4
}

will have no cars but a hyperloop system that is able to transport anyone to any place on the line in no more than $20 \mathrm{~min}$. In essence, the city is composed of 'three layers' or 'tubes' - three lines: a walking layer, below that a high speed transportation layer that moves people using the hyper-loop technology, and a third, deeper layer that contains services and utilities. The city which is called Neom ('New Future') or more colloquially The Line, will be carbon neutral, economically vibrant with employment based on high tech, and pollution-free. So little has been worked out however, that its plan so far is no more than a line across the region of Tabuk in the northwest corner of the country (see https://www.neom.com/enus/whatistheline). Needless to say, it has attracted severe criticism as an indulgence by the rich and powerful. 
If Brasilia was unable to adhere to the form imposed by its masterplan, then how do you suppose development in Neom can be controlled to rigidly keep to the Line; only by severe restrictions that would limit the most basic freedoms. In contemporary cities, people move according to the time, cost and distance incurred by visiting activities removed from places where they live and work. Tobler's (1970) law states “... everything is related to everything else, but near things are more related than distant things ...", and it operates everywhere. In Neom, unless you are forbidden from actual travelling to meet anyone or from interacting with anything at different distances away from you which would be impossible, some places near the centre of the Line will be much more accessible than those at each end. People and activities will begin to adjust with respect to their ability to pay for different levels of accessibility and the Line will become differentiated with respect to the value of different locations. The ultimate form of the city will thus be no longer uniform and linear.

We will begin by sketching what we know about ideal cities based on linear forms, and how these forms have been almost impossible to maintain as they collapse towards a relatively stable equilibrium. We will then propose a simple geometric representation of an ideal linear town and then suggest how population units that occupy the form interact with one another using a variant of Tobler's Law. This suggests a process whereby the population units move towards sites of greatest accessibility which is akin to introducing distance between those parts of the city that define adjacent units spanning the line. This enables us to state a formal equilibrium that shows us how a stable form emerges which we demonstrate first for the line, maintaining its integrity but allowing populations to move to any of the cells defining the units which people occupy along the line. This process retains the linearity of the city but changes the numbers of population in each of the locations. The outcome is to an extent obvious. The uniform distribution of population is transformed to one where population (and its density for each unit has the same area) is proportional to the accessibility of each location.

We then relax this assumption that the only permissible locations lie on the line. We assume the line defines an axis across a space which is a grid of locations. The initial city is the uniform population along the line and we then compute accessibilities across the entire grid. Locations which are not part of the line have accessibilities and we then begin to populate the whole space with respect to adding population in proportion to these accessibilities. We then modify this to only consider new populations with respect to the highest accessibilities and then we examine the situation where locations that are not already populated are considered for growth. These alternatives lead to city forms that are much more likely to resemble our contemporary cities in terms of shape and polarity, and essentially demonstrate the futility of building cities whose form ignores the functions that determine how we locate and move in the real city.

\section{The history of the Linear City}

Ideal cities have been proposed by philosophers and architects since antiquity and they all share the common characteristic that they are composed of relatively simple geometries, most reflecting the straight line, the grid, the circle, and just occasionally the flowing line. Most have been new cities which begin small but as they grow and develop, lose their ideal form as a multitude of locational decisions made by the population crowd in on the original plan. Greek and Roman castra are perhaps some of the clearest examples where the residuals of these grid iron plans used to organise the structure, are still evident at a very small scale in cities that have grown dramatically since they were first established as encampments. The extreme form of this idea is the linear city where like Neom, population is spread out along a line which invariably provides a transportation artery enabling interaction with both near and far neighbours who live on either side of the line at different distances away from each other but adjacent to the country and agriculture which sometimes provides their livelihoods. The classic example was proposed in 1882 by Arturo Soria y Mata who suggested such a linear form configured as a horseshoe shape encircling much of Madrid, organised around a tramway not more than $500 \mathrm{~m}$ wide so that it could grow in a straightforward manner at either end (Boileau, 1959). In the event, only a $5 \mathrm{~km}$ segment was built with the development stopped in the 1930s by the Spanish Civil war. Today La Ciudad Lineal as it is called is absorbed into the sprawl of greater Madrid, in much the same way the plan for Brasilia has become a residue, perhaps a victim from an earlier era as the growth of the city has surrounded it. In fact, Soria y Mata considered such linear development the obvious and 'optimal' way to grow a city, echoing much later ideas about cities as fractals when he said: "The growth of linear cities is simple because the line itself can go on to infinity and at any point a new community can shoot off like the branch of a tree, the tributaries of a river, the veins of the body", quoted in Furundzic and Furundzic (2013).

The first 30 years of the last century saw many proposals to develop linear settlements, also referred to as strip cities, ribbon development, and corridors. Tony Garnier's Cité Industrielle reflected his ideas about the optimal city which suggested strong linearity of form (Wiebenson, 1960). The emergent Soviet Empire also had its fair share 


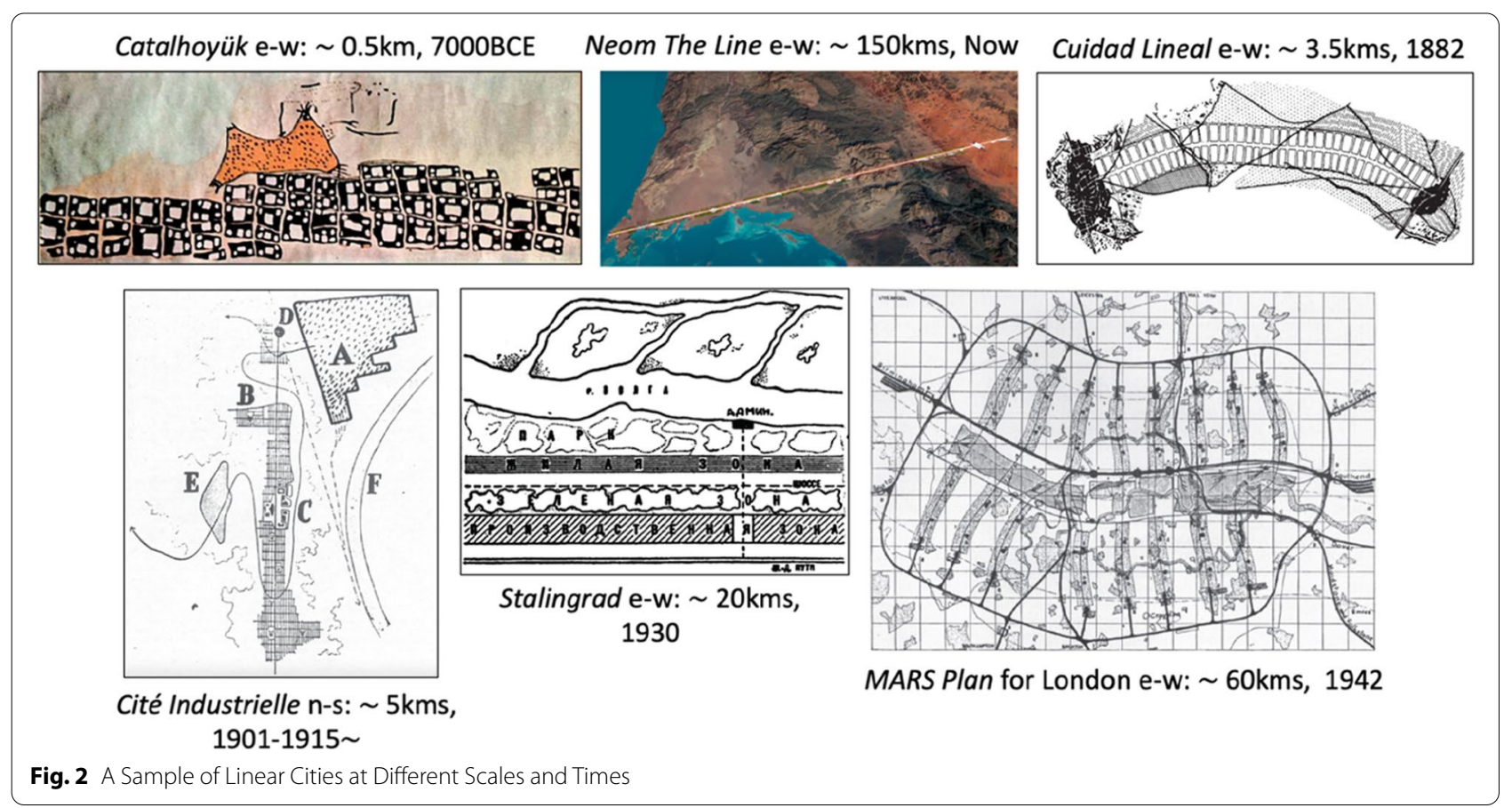

of adherents to the linear city ideal which it was argued provided a sufficiently flexible form to embrace continued relentless expansion of manufacturing production lines as in Nikolay Milyutin's (1930) plan for the socialist city. These ideas were outlined in his book Sotsgorod and in many proposals for Soviet cities such as in Ernst May's plan for Magnitogorsk. In particular, Milyutin's plan for Stalingrad used the natural features of the Volga to impress his ideas about linear growth in the form of a 'strip city' using a strict parallelism of zones of different land use (Antyufeev and Antyufeeva, 2019; Collins, 1959; Doxiadis, 1967). Many of these ideas were taken up by groups of architects who saw the city more as a work of art than a living system, more as a machine that could be designed using simple principles of interaction and location than an organism whose own forces held its dynamic structure together.

In the 1920s, the architect, Le Corbusier, one of the pioneers of the modern movement, also began to speculate on the shape of idealised cities beginning with strongly radial and circumferential forms but rapidly evolving his ideas into a much stricter geometry - the linear. With Soria y Mata's La Cuidad Lineal as inspiration, he devised what he called the Ville Radieuse into a city form that mapped various geometric lines and the location of key urban activities into a shape that reflected the disposition of functions within the human body (Corbusier, 1935). He aggressively promoted the idea through several of the CIAM conferences on modern architecture and then through his Athens Charter. This had an enormous influence on the design of public housing after the second world war but he had an impact on one of the most radical linear city ideas ever proposed by the Modern Architectural ReSearch group (MARS). Corbusier's thinking also permeated the Bauhaus and it was Ludwig Hilberseimer who proposed linear-like residential structures which influenced the architects in MARS. The group which evolved itself through various ideologies about the form of future cities, produced a plan for London whose form was to be based on 8 radial strips, north and south of the Thames making 16 strips in all, a little like taking Soria y Mata's La Cuidad Lineal and splaying it north and south of the River, replicating it 16 times. The plan which was ultimately published in 1942 contrasted markedly with how the London actually functioned and in hindsight, it almost represented an ongoing thought experiment in fictional geometries for the future city. Gold (1995) provides a fascinating summary of the social dynamic in preparing the the plan over a period of some 10 years. We show a sample of these linear forms in Fig. 2.

The properties of these ideal cities were not wellworked out by their proponents. Apart from the general notion that a linear structure directs transportation that can be easily accessed if development is kept to within walking distance of the line or spine, and that the countryside is equally accessible on either side of the line, there is rarely any discussion of overall 
accessibility. However several examples do suggest that such lines can join more conventionally configured radially concentric clusters together, thus increasing overall accessibility. In fact, March (1967a, b) argues that if one assumes a central place hierarchy where the hubs simply represent points where linear strands of development come together, then rather than focussing all the development on the hubs, it can be spread out over the lines joining the hubs. In this way, the proposed form increases the accessibility of each unit of development with respect to any location within the structure but this argument also depends on the density of development and on the width of the linear strands. Nevertheless, as March (1967b) points out, this style of ribbon development does have advantages. He says:

"I could argue that the forces behind the most spontaneous and energetic form of urban growth to have occurred this century in this country, namely ribbon development, are seen to be not only rational, but economical in respect of roads and services. And that, paradoxically, if these forces had been directed to create planned ribbons, the feeling of builtupness in the country as a whole could have been less, not more, than today's emphasis on urban envelopes will produce" (March, 1967b, page 335).

There are other linear structures that have been used to describe contemporary as well as ideal cities which focus not on cities built along a simple line but on many lines. Space syntax has been developed to enable cities to be represented as constellations of lines and Hillier (1996) has proposed several idealised configurations which are used to define streets. There are many discussions of streets and patterns by various urbanists, see for example the work of Marshall (2005) amongst others, while more formally the whole body of network science which has developed rapidly over the last 20 years, is relevant to the broader discussion. At one extreme, there are examples of cities without streets at all, largely in the oldest urban settlements such as those in Asia Minor and Mesopotamia. At Catalhoyük in Turkey, there is what archaeologists consider a map of the settlement that has no streets and where the current interpretation is of a place where the inhabitants worked out of doors on an elongated deck of sorts into which were punctuated the various dwellings (Hodder, 2005). The plan of the village shown in Fig. 2 is probably the world's oldest map despite some controversy (Clarke, 2013). Catalhoyük is over 9000 years old and its origins came well before the world invented wheeled technologies, thus impressing on us the power of technology in suggesting and guiding the development of various urban forms.
This brings us back to Neom. In Fig. 2, we illustrate the only plan that appears to have been published for the city although it is not possible to picture any detail of development over the $170 \mathrm{~km}$ span. Neom depends on two key principles: the latest technology to enable the city to remain connected across its length; and access to open space from within the modules or the clusters that make up what essentially might be like a series of beads on a necklace. These two principles are consistent with the move to net zero carbon emissions and a healthy life style through people interacting using active travel to local amenities and facilities. The unsustainability, however, of Neom is that no other principles relating to location, interaction and density are invoked. The hype that has accompanied its launch (even advertisements on UK commercial TV) suggests many aspects of the future city that are mere aspirations. The brochure says: "It's an attempt to do something that's never been done before and it's coming at a time when the world needs fresh thinking and new solutions ... part of building a new model for sustainable living, working and prospering".

Yet the denunciations have come thick and fast. Gordon (2021) says:

"If techno-futurism has perfected anything, it is the art of unwittingly re-inventing old ideas, inflating them to a scale so epic that it accentuates all of the idea's flaws, and presenting it in a slick hype video as the Only Way Forward."

Worth (2021) writing in the New York Times says:

"Now the Saudis have announced a fantasy that makes all their previous efforts look tame ..." calling the Line "... 'a civilizational revolution' to be inhabited by one million people 'from all over the world' Why anyone would want to move there, and why a city should be shaped like a strand of capellini, is anyone's guess."

Let us give the last word in this rapid historical perspective on the linear city to Jane Jacobs (1961). Her thesis has always been that cities are messy affairs, highly diverse, full of essential tensions and contradictions that give them their true vitality. In speaking of idealised forms, the brain child of those architect-planners who believe it is their role to pronounce, she says:

"When city designers try to find a design device that will express, in a clear and easy fashion, the 'skeleton' of city structure (expressways and promenades are current favourites for this purpose) they are on fundamentally the wrong track. A city's very structure consists of a mixture of uses... We get close to its structural secrets when we deal with the conditions 


\section{$T \leftarrow, i, \ldots \ldots \ldots \ldots 1$ CENTRAL SEED SITE $1 \ldots \ldots \ldots \ldots \ldots, t \ldots \ldots \rightarrow \rightarrow T$ $x_{L 8}$

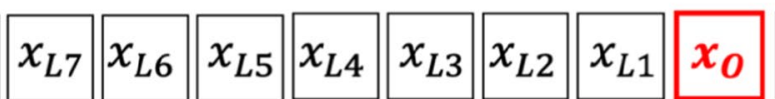 \begin{tabular}{|l|l|l|l|l|l|l|l|l|l|}
\hline$x_{R 1}$ & $x_{R 2}$ & $x_{R 3}$ & $x_{R 4}$ & $x_{R 5}$ & $x_{R 6}$ & $x_{R 7}$ \\
\hline
\end{tabular} left hand wing \\ right hand wing}

Fig. 3 Formal Representation of the Linear City

\section{that generate diversity" (Jacobs, 1961, page 376).}

Diversity of course is not what cities on a line are capable of generating, at least as long as the line is strictly maintained. We will now demonstrate this formally.

\section{A spatial representation of the Linear City}

We begin with an assumption that a linear city is a set of regular units or cells strung out horizontally and uniformly in sequence, like beads on a string. The development of such a structure takes place with the city expanding in both directions from a central seed site that we define by the coordinate index $x_{o}$. The progression that we assume which is the growth path of the city, adds two cells at time $t$, each cell being on opposite sides of the central seed site. These cells are indexed as $x_{i}$ in one direction and $x_{j}$ in the other where these indices are not only the locations of the cells but are associated with the time when the cells are first developed. In short, the cells develop in sequence as $x_{i}, i=1,2,3, \ldots . T$ and $x_{j}, j=1,2$, $3, \ldots . T$ where $i$ and $j$ are also $t$, and $T$ is the total number of time periods defining the growth process. We illustrate this sequence in Fig. 3.

We will generate a succession of two cells each containing one unit of population defining two households which we call $P_{i}(t)$ and $P_{j}(t)$. The growth process is

$$
P(t)=P_{i}(t)+P_{j}(t)+1=\lambda t+1, \quad i, j, t=0,1,2,3, \ldots, T,
$$

where $\lambda$ is the growth rate and unit 1 in eq. (1) is the seed household at $x_{0}$. In Fig. 3 , the first variable $P_{i}(t)$ determines the cell $x_{i}$ on the left-hand side of the source $x_{o}$ and the second variable $P_{j}(t)$ the cell $x_{j}$ on the righthand side of $x_{o}$. The linear growth rate $\lambda=2$ is simply based on adding two cells at each time period, the one on the left hand side, the other on the right hand side. From the start of the process at $t=0$, the sequence of household populations generated is $1,3,5,7,9,11, \ldots$. This is the simplest growth process consistent with a city linear in space and time; we will adapt this to a more complex nonlinear process below but to take this model further, we need to explore how its cells interact with one another.

The ability of any two cells to interact is also a key feature of this model but in all the examples of linear cities that we introduced earlier, such interactions are missing, assumed to be zero or simply not stated. Indeed if there are any assumptions at all, it is that such interactions are constant with relative distance between the cells that make up such linear structures not playing any part. Here however distance is a key feature of our representation and we thus proceed as follows. Each cell is defined by its locational index $x_{z}$ and the Euclidean distance $d_{x_{n} x_{m}}$ between any two locations $x_{n}$ and $x_{m}$ is stated as follows:

$$
\left.\begin{array}{l}
\text { if } x_{n} \in i \text { and } x_{m} \in j \text {, then } d_{x_{n} x_{m}}=i+j \\
\text { if } x_{i}>x_{i^{\prime}} \text { then } d_{x_{n} x_{m}}=i-i^{\prime} \\
\text { if } x_{j}>x_{j^{\prime}} \text { then } d_{x_{n} x_{m}}=j-j^{\prime}
\end{array}\right\}
$$

In defining distance between any two cells, we can assume that this relates to the interaction between them which we define as an inverse function

$$
T_{x_{n} x_{m}} \propto f^{-1}\left(d_{x_{n} x_{m}}\right)
$$

Equation (3) lets us compute a simple accessibility or centrality for each cell as $\sum_{m} f^{-1}\left(d_{x_{n} x_{m}}\right)$ that shows how these cells might be differentiated. We will develop a number of these later in the paper but here we will state a particularly simple measure based on the inverse square law that defines the accessibility of a cell $x_{n}$. This is defined as

$$
A_{n}=1 / \sum_{m} d_{x_{n} x_{m}}^{2}
$$

and it is easy to see from these accessibilities which we scale and illustrate in Fig. 4 that the central cell $x_{o}$ has the highest accessibility $A_{o}$.

We can also assume other growth processes where the number of cells generated at each time period more 


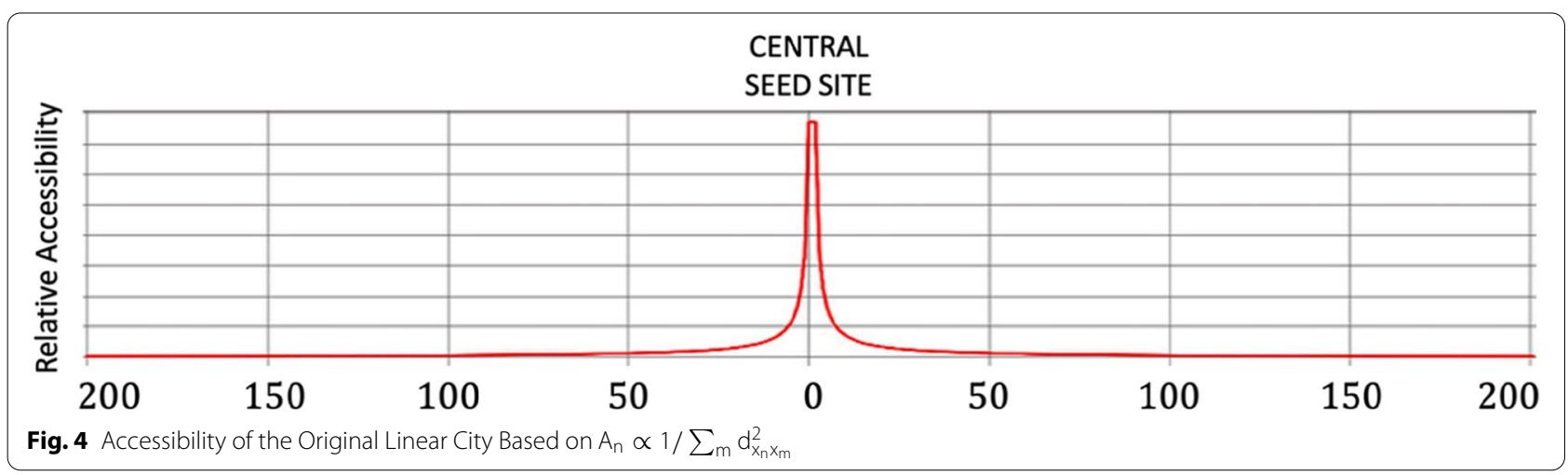

than doubles if we increase the rate $\lambda$, noting that to generate whole households the rate should be integral, that is $\lambda=1,2,3, \ldots$.. If the rate is real, then it is necessary to introduce rules that ensure the household and cell are discrete, and if a different non-linear growth process is specified such as $P(t)=t^{\lambda}+1$, then we need to define rules that convert the cells into an exponentially growing sequence of cells located on each side of the central seed site $x_{0}$. In this paper however, we will focus on the simplest model which is linear in terms of growth, both spatially and temporally.

However any serious model of urban structure must also adopt the principle that populations are intrinsically mobile with respect to a) daily patterns of movement such as journeys to work, shop, entertainment and so on as well as to b) movements over longer periods of time as populations adjust to the changing urban landscape that provides them with various opportunities for housing and jobs. These involve more permanent changes in location. We have already noted that we can define a volume of spatial interaction as $T_{x_{n} x_{m}}$ which depends on distance or travel cost between different locations. In fact, in the simplest linear cities from La Ciudad Lineal onwards and particularly for the recent proposal for Neom structured along The Line, interaction between the cells or locations is assumed to be based on a uniform friction of distance; in other words, populations are assumed to interact regardless of how distant they are from one another, even though the hyperloop technology in Neom would still embody a friction of distance. The implication is that the interaction potential is the same from any cell to any other, that is, that the notional distance $d_{x_{n} x_{m}}$ is constant or even zero. Thus Tobler's (1970) Law does not apply. This almost smacks of teleportation, but in essence, the notion that people will travel in the way assumed is an extreme fiction, and if any such city were to be built, it would soon begin to unravel and collapse to the sort of urban forms that characterise cities that evolve from the bottom up, in fact, as most cities do which we will show here.

We now need to dimension the linear sequence of cells so that it accords to what is as close as possible to the proposed shape. In the case of Neom, the proposal is for the city to be built on a more or less straight-line of $170 \mathrm{~km}$ in length, eventually with a population of 1 million. If each individual were to be arrayed along this line, they would be compressed shoulder to shoulder at an interval of about $20 \mathrm{~cm}$ between each which is extremely congested. If we assume that a household were composed of an average of 4 persons, then the households would be spaced $2 / 3^{\text {rd }} \mathrm{s}$ of a metre apart. In fact the proposal is that households be aggregated into neighbourhood modules which are composed of four clusters, and although the size of these clusters and modules is not specified in the Neom proposal, we will assume that a cluster consists of 150 households with each module composed of 600 households or 2400 persons. If we array the modules, then there would be about 420 along the $170 \mathrm{~km}$ line and they would then be spaced at about $400 \mathrm{~m}$ between each. Immediately you can see that populating the line in such a way leads to unacceptably high densities if the module is compact and constrained within the space available. It does not appear that the geometry of the city has been accounted for with respect to these constraints.

To proceed with a structure like Neom, we will assume that the line is divided into 400 modules each with an internal circulation pattern based on walking. To ensure we are dealing with round numbers, we assume the line is now $160 \mathrm{kms}$ and thus the 400 modules are spaced at some $400 \mathrm{~m}$ between each, nearly half a kilometre, and if it is assumed the unit cell is square, then the area of the cell is $0.16 \mathrm{~km}^{2}$. If each unit has 2400 persons, the density is about 15,000 persons per square kilometre. London has 5000 while Shanghai has about 13,000. In fact much depends on the area taken and in this calculation we have not assumed any other land take within the city. In practice even in a place like Neom, the densities will 
be much lower than this. However we will make use of this template of 400 cell units for 2400 persons in each giving some 960,000 persons spread over a line which is now $160 \mathrm{kms}$ in length. In this sense, the structure is linear but the beads along the string are now integrated neighbourhoods that we treat as indivisible cellular units.

\section{Defining a spatial equilibrium}

We will assume that the 400 modules that compose the linear city are represented by 200 modules defined by their locations $x_{n}$ to the left of the seed site $x_{o}$ and 200 to the right $x_{m}$. We define the interactions between these locations as $T_{x_{n} x_{m}}$ and the distances between them as $d_{x_{n} x_{m}}$ but we need to refer to these as any pair of locations over both left and right series of locations which run from $x_{200} \ldots x_{1}, x_{0}, x_{1 \ldots} x_{200}$; thus we can define any two locations across this range as $r$ and $s$. We now state the generic flow $T_{r s}(t)$ from eq. (3) as

$$
T_{r s}(t) \propto P_{s}(t) d_{r s}^{-\alpha},
$$

where $t$ is time (or iteration), $P_{s}(t)$ is the population in cell $s$ at time $t$, and $\alpha$ is the friction of distance parameter. In most linear cities including Neom, the assumption is that $d_{r s}^{-\alpha}$ is a constant or in fact is zero, thus implying there is no physical variation between cells $r$ and $s$, and in the case where there might be physical movement, the population is initially $P_{s}(1)=1, \forall s$. The total volume of travel where it physically takes place at any time is constrained to the total population, that is $\sum_{r} \sum_{s} T_{r s}(t)=P$.

The key assumption in Neom is that there are no individual movements other than walking within modules or between them but if any distance is to be traversed, it is to be accomplished by hyperloop technology. This as one might imagine is unspecified for the physical constraints on where one might access the loop are not worked out. In fact, if the only way to travel any distance other than by walking is using this technology, then the access points to the hyperloop need to be clustered at the locations of the neighbourhood modules and there are far too many of these (400) for this to be possible. Most of the time travelling would be in accessing the trains and in any case, with current technologies, it would not be possible to keep to appropriate headways (Hanson, 2020). In short, the proposed basis for long distance travel in such linear cities is simply not tenable.

The problem with specifying a linear city in the way proposed is that there is no sense in which the city is in equilibrium. If we array individual units in such a sequence, their relative positioning makes a difference to how close they are to one another. The central seed site $x_{0}$ is the most accessible using the formula in eq. (4) as we have shown in Fig. 4 but the distribution of population $P_{s}(1)=1, \forall s$, at the first time $t=1$ is uniform across all cells. In fact in real cities, accessibility defined in these terms is usually highly correlated with population. The implication is that if the constraints on the location of population were to be dropped in linear cities like Neom, the population would quickly adjust to a new equilibrium.

This is the core relation in our analysis of cities in equilibrium and we define it from the following equation

$$
P_{s}(t+1)=P \sum_{r}\left[P_{s}(t) d_{r s}^{-\alpha} / \sum_{s} P_{s}(t) d_{r s}^{-\alpha}\right]
$$

Equation (6) illustrates that the equilibrium is based on a simultaneity between population in the different cells and their accessibility. If an equilibrium exists, then $P_{s}(t+1)=P_{s}(t)$ and this can be derived by starting the iterative sequence from $P_{s}(1)=1, \forall s$. From the data we have specified, we have explored this for the 400 module linear city ${ }^{2}$ first using an inverse distance law with different values of $\alpha$, and then computing the distribution of population from eq. (6). In fact it appears that the city is almost in equilibrium as soon as the movements set off to meet the equilibrium condition in eq. (6) are initiated whereas the shape of this equilibrium is most sensitive to the parameters of the inverse power function. In Fig. 5, we show the equilibrium computed by iteration on eq. (6) for the functions $d_{r s}^{-0.5}, d_{r s}^{-1}$, and $d_{r s}^{-2}$ and we also contrast this with a negative exponential function $\exp \left(-0.1 d_{r s}\right)$ which converges much faster to an equilibrium than the power functions.

It is clear from the progression of moves, that the most accessible point - the seed site - attracts more and more population and although we have not explored this formally, we are guessing to the ultimate outcome being a singularity that is obvious from the geometry. This however is an almost fictional interpretation of the equilibrium involving the process of starting with a uniform distribution of population mandated by the designers of the city. The process begins where people move in response to the variations in accessibility which produce a new distribution of population, i.e. $P_{s}(2) \neq P_{s}(1)$, $P_{s}(1)=1, \forall s$ and it continues until an equilibrium of some sort emerges. This process of continued relocation is likely to occur very slowly over time with population physically relocating in response to the changing pattern of accessibility that is formed as populations relocate. Given the 400 modules comprising the original sequence,

\footnotetext{
${ }^{2}$ In fact there are 401 cells or zones in the city arranged around one central seed cell $x_{o}$ with two linear arms left $L$ as $x_{L 200}, x_{L 199}, x_{L 198}, \ldots, x_{L 1}$, to the central seed $x_{o}$ and then from the seed to the right as $x_{R 1}, x_{R 1}, x_{R 3}, \ldots, x_{R 200}$.
} 

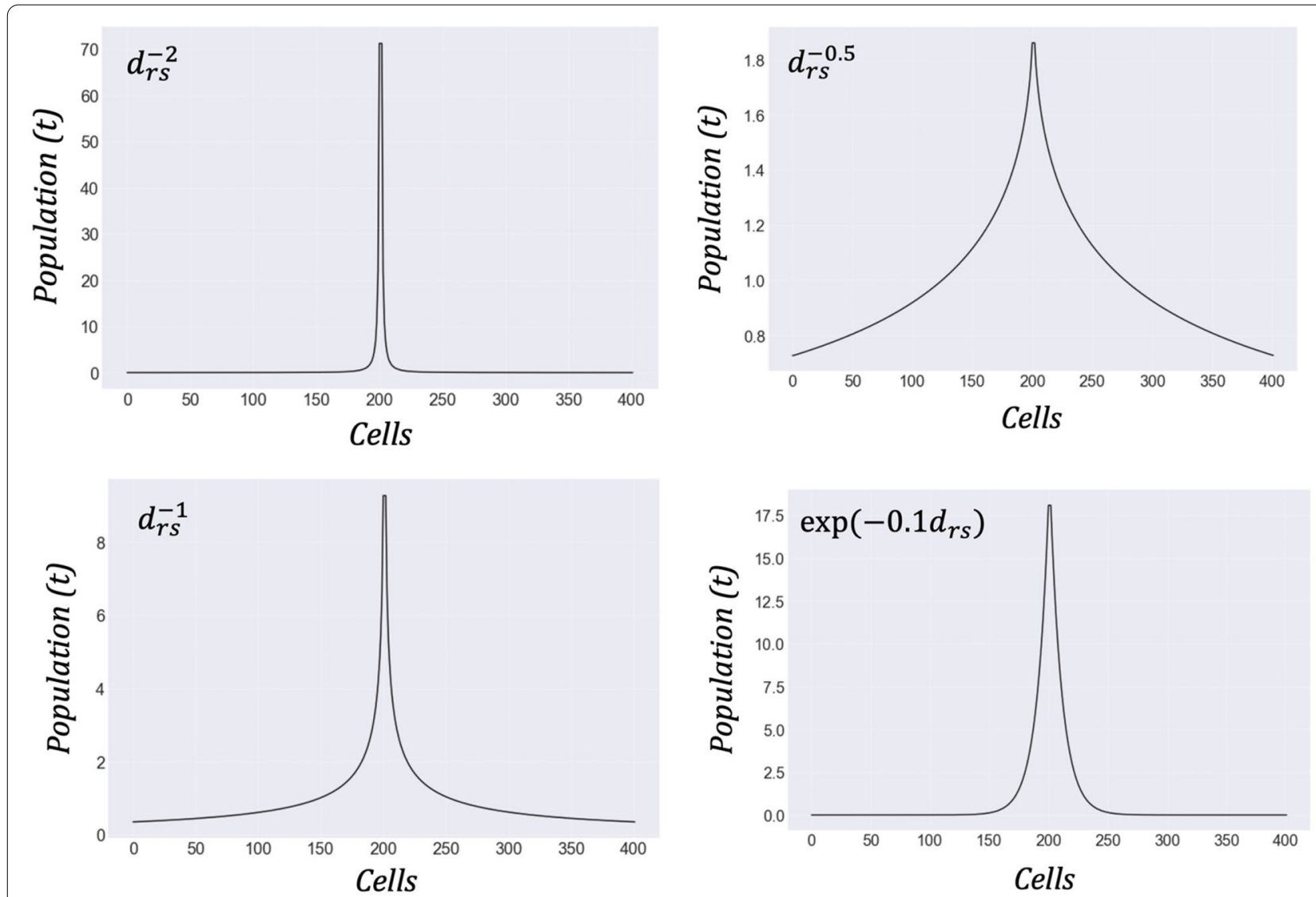

Fig. 5 Agglomeration to a More City-Like Form. The graphs are profiles across the 401 cells on the horizontal axis where the seed site is the central site. The vertical axis is population scaled to sum to the total population which for each example is 401 units

with some 2400 persons in each neighbourhood module, then it might be possible to demonstrate a slow movement of population from these modules that could be fitted to a feasible evolution of such an equilibrium, even perhaps in a real city. In fact the differences between each iteration with respect to populations in the series of cells, fall very rapidly at first and within 10 iterations to all intents and purposes, the new population distribution measured by $\sum_{s}\left|P_{s}(t+1)-P_{s}(t)\right| / P_{s}(t)$ is within $1 \%$ of its previous value for each of the four functions shown in Fig. 5. There is little point in iterating these functions much further for after about 25 iterations to all intents and purposes the equilibrium is reached. It is worth relating the way we define population and distance to accessibility through other attributes of location that define the urban economy, specifically the rent payable and travel cost incurred. We can relate accessibility $A_{n}$ to rent and distance to transport cost $d_{0 x_{n}}$ and note that the utility that is gained at each point can be defined as $A_{n} d_{0 x_{n}}$. This relates our analysis to maximising utility where rent payable and transport cost can be viewed as economic goods
- land and distance - that can be easily related to their demand (Henderson and Quandt, 1958).

\section{The polycentric Linear City}

Linear cities usually have one central seed site and although historically, cities tend to only have one core, since the industrial revolution as cities began to grow and new technologies enable rapid movement to distant places, a degree of polycentricity has emerged. Many cities have begun to fuse into one another with multiple centres occurring within urban agglomerations manifesting a hierarchy of centres of different sizes. These sizes are likely to be conditioned by some economic principle of agglomeration such as that defined in central place theory but here we will simply choose a relatively arbitrary hierarchical subdivision of the line and choose different sizes of subcentre. Let us adopt a binary hierarchical subdivision where we begin with 401 cells and around the central cell, divide the remaining 200 cells either side into two sequences of 100 in the following manner. At the top of the hierarchy, we first divide the 400 cells into 2 . Then we divide the 200 cells in each branch of the 

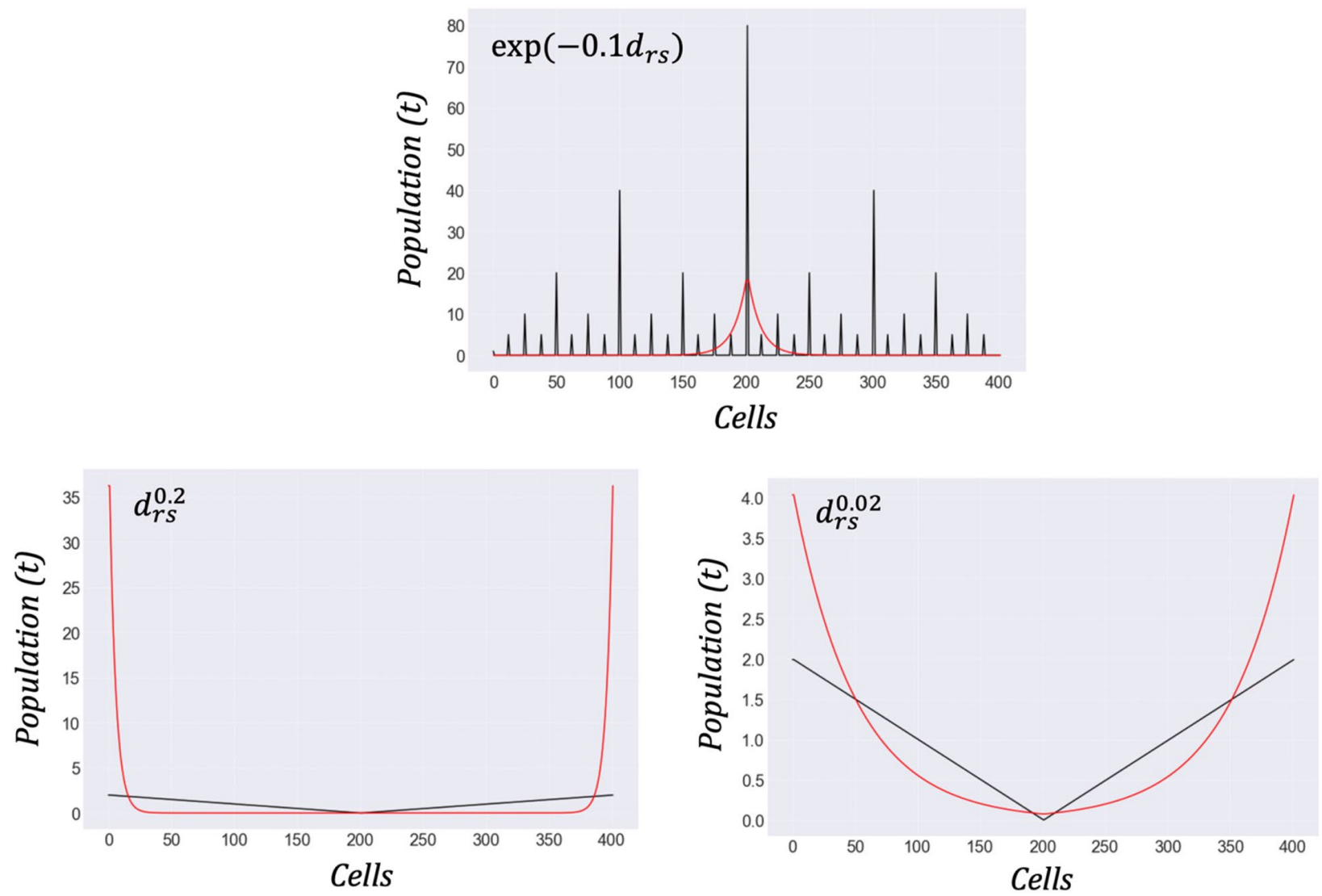

Fig. 6 Multiple Centres and Edge City Effects. The black lines show the distribution of population as arranged in a hierarchy in $6(a)$ and as edge effects in $6(b)$ and $6(c)$. The red lines show what the ultimate outcomes for each of these three cases as the system moves towards equilibrium.

hierarchy into two sequences of 100 . We continue in this fashion and at each stage in the hierarchy, we compute the number of new subcentres as $n(h)=2^{h}, h=0,1,2,3$, .... which follows the sequence of numbers of subcentres $n(0)=2^{0}=1$ and then $2,4,8,15,32=n(5)=2^{5}$. The total number of centres across the line is computed from $m(h)=2^{h+1}-1$. We show this sequence in Fig. 6(a) noting that we can increase the density of polycentres by moving to finer subdivisions at each level, using larger generative factors such as $n(h)=3^{h}, n(h)=4^{h}$ and so on.

Using this algorithm, the polycentres are shown at equal spacing of their subdivisions in Fig. 6. We have also specified the hierarchy down to level $h=4$ where we have arbitrarily specified the size of each of these centres so that they add to 250 units. In fact there are some 31 units that contain these giving an average of about 8 households for the polycentres. The remaining 469 units need some level of population and thus we assume that each of these modules has 150/469 units which is about 0.31 units per cell. As these values are all relative and only used to show the attraction of populations, then we do not need to worry about the nature of the units as long as the attractions remain relative to one another. This is easy to see for the algorithm that enables the equilibrium to be computed in eq. (6) is independent of scale, that is, their relativity is preserved no matter how population is scaled.

When we run the model, we find it impossible to break the intrinsic symmetry of the line around its seed. The power of the central site is so great that even when we space significant populations at the different scales of hierarchy, we cannot break the agglomerative forces that move populations towards the central seed site. In fact the hierarchical distribution around the central seed site reinforces the larger concentration towards the central site and it is not surprising that the picture that emerges wipes out the effects of the polycentres other than the central seed. In fact if we position the population towards the left and right edges of the line, that is at $x_{L 200}$ and at $x_{R 200}$ which in terms of the list of sites are $x_{1}$ and $x_{N+1}$, we still find it difficult to break the focus on $x_{0}$. In fact we can just about do this by pumping these populations/ attractions at the extreme ends of the line ever higher but in essence, the initial geometry is hard to fracture 
with respect to the accessibility of the central point. In Figs. 6(b) and (c), we look at two cases where we arrange the population so that it increases as either end of the line is approached and show the ultimate distribution in equilibrium. Despite this demonstration of the power of geometry in cities, it also illustrates how hard it is to depart from systems such as cities which grow from single seed sites.

Of course, the population is an attraction profile that is likely to be correlated with many other activities. For example, the population attracted to each cell gives a measure of population density with the central core the highest and the decline in densities quite characteristic of real cities. The same might be assumed with respect to the price of land or rent which also declines in the same way, so in fitting such a model these would be the indicators to examine. However this is but another index of how infeasible such a linear structure might be in that it takes no account of variable demand, different preferences for urban living and so on. These are all features that come to bear on how such a city were to actually develop if the developers at some point were to take off the constraints and regulations on how land could be developed and how people might travel. Page (1999) develops a hypothetical geometric city form whose rules establish different economic equilibria not dissimilar from the process we use here. There are other models consistent with urban economic theory that focus on how individuals locate to maximise their utilities in different geometrical contexts but these tend to start with micro-economic theory and then show how the equivalent model can be distorted with different geometries rather than starting with different geometries and building equivalent models. This represents another dimension to this work where we refer the reader to Solow and Vickery (1971) and Wang (1993).

\section{Transforming one-dimension into two}

So far we have kept the intrinsic linearity of urban form and have simply shown how agglomeration economies are simulated by computing the accessibility at different points along the line. We began with each point on the line weighted equally in terms of its contribution to the accessibility and it is the relative distances between each point and all others to which it can be linked that determine its actual accessibility. There are several different ways of keeping the city on the line and determining the population density of each point according to different forms of accessibility as we have just illustrated but to demonstrate how the city may radically depart from the line, we need to consider all the potential space around the line. The easiest way to do this is to consider the new city area as a square grid 401 units or clusters by 401 which generates a total of $401^{2}=160,801$ zones or locations any of which can interact with any other. What we should now do is rework the logic of the last section computing accessibilities for each of these locations and this would require us to initiate some $160,801^{2}=2,585,696,160$ calculations several times over. It is impossible to run the model at this scale for it requires more than 2.5 billion operations simply to compute a basic accessibility, and thus for us to proceed, it is very clear that we need to reduce the scale of the problem. Rather than a 401 unit line we define one 20 times smaller, working with a grid of $21^{2}=441$ zones. In this mode, our style is one of demonstrating an exploration of the properties of the linear city from which we 'assume' we can generalise. In fact the regularity of the processes involved are such that we have some confidence in being able make such an assertion.

We now need to also generalise the interaction model and the equilibrium conditions to the square grid. We will define an augmented spatial model based on a gamma-like distribution function which has two deterrence (distance) components. This can be stated as

$$
f_{r s} \propto d_{r s}^{\beta} \exp \left(\gamma d_{r s}\right)
$$

where $\beta$ and $\gamma$ can be tuned to reflect the interaction between centralising and decentralising effects. There are four possibilities: first if $\beta<0$ and $\gamma<0$, then the effect is to heavily concentrate development close to its original source and this would keep the focus on the line relatively intact. Second if $\beta>0$ and $\gamma>0$, then this would push development to the edge of the system, away from its original source. With the other two combinations $\beta>0$ and $\gamma<0$ and $\beta<0$ and $\gamma>0$, it is not possible to guess the balance of forces in advance. However these forces would operate relentlessly from the initial conditions where all unit populations located on the line. In the first time interval $t=1$, there are 420 empty locations to be considered and there are different ways these might be populated once the initial clusters on the line are given the opportunity to move as they search for locations that optimise their accessibility.

Following eq. (6), the equilibrating process can be stated again as

$$
P_{s}(t+1)=P \sum_{r}\left[P_{s}(t) d_{r s}^{\alpha} \exp \left(\gamma d_{r s}\right) / \sum_{s} P_{s}(t) d_{r s}^{\alpha} \exp \left(\gamma d_{r s}\right)\right]
$$

where we now weight the gamma-like function with the population $P_{s}(t)$ from the previous time period. At the beginning of the process, the population in the locations off the line are all zero and in this first time interval, we need to enable these by excluding the measure of 

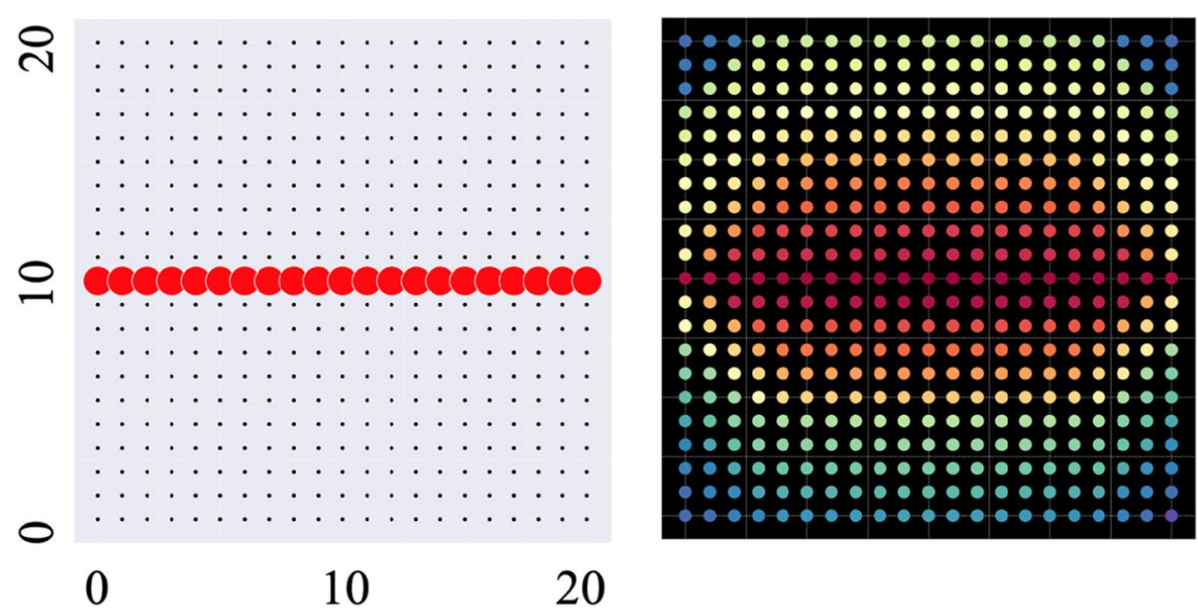

Fig. 7 Spreading the City on a Line into the Two-Dimensional Space. a) The original line left, and right b) temporal colouring, starting with the line spreading out, but retaining a measure of linearity

population from the distribution function. Therefore we set this as

$$
P_{s}(1)=P \sum_{r}\left[d_{r s}^{\alpha} \exp \left(\gamma d_{r s}\right) / \sum_{s} d_{r s}^{\alpha} \exp \left(\gamma d_{r s}\right)\right]
$$

and using $P_{s}(t=1)$, we then initiate the process of iteration implied in eq. (8). This is likely to converge due to the fact that the process is consistent, regular and wellbehaved and the basic spatial form is symmetric.

We will explore three variants for showing how movement towards an equilibria can be defined by maximising local accessibilities. The first variant is where the locations defined on the original line, do not change in their population but that at each time period, a new unit of population is located in the empty cell that has the highest accessibility. This occurs one at a time and once the location is populated, it cannot be repopulated or lose population. So this process starts with the original 21 units on the line across the region, and then each of the remaining 420 locations are populated in order of their highest accessibilities. Ties are broken arbitrarily but the final total population is ultimately the number of cells in the space, namely 441 . As the process occurs one cell at a time, the space fills up and as the time $t$ reflects the strict order of computation, we can colour the sequence of cells coming on stream according to this variable. In Fig. 7, we show this sequence and this provides a catalogue as to what cells get developed where and when. You can see the city spreading out and ultimately becoming ever more monocentric around the centre of the space which is the centre of the line. The original line is still part of the pattern but it gradually reduces in strength. The units on the line are shown in 7(a) as the starting point for this and subsequent variants while in 7 (b), the pattern is coloured by time across the spectrum from red-brown to blue.

We can easily adapt this process to scaling the locations according to the level of accessibility at each location. We scale the population (which we assume as the total number of units (441)) and in Fig. 8, we show this process where both colour is used for the temporal location and each circle is proportional to the size of population in each unit. Note that in these two cases, we have assumed that the only deterrence is the first distance effect and we thus set $\beta=-2$ with $\gamma=0$. This is in effect the inverse square law but of course we could use any variant of the function in eq. (7). We have explored some of these more casually and they do not produce any real differences from the outcomes that we show in this section. We should also note that the order in which locations are considered occurs according to the labelling of cells and this does occasionally impose some asymmetry on the form. In fact this does occur in Fig. 7 where the horizontal line across the square grid continues to be reflected in the ultimate spread. But this is not so in Fig. 8 where most of the asymmetry that we can clearly observe as the sequence of iterations moves towards an equilibrium, is ironed over the 100 iterations used to show that an equilibrium occurs.

We will now show how different values of the parameters of the function $f_{r s}$ in eq. (7) control the spread into the space. The default model that we again use is where $\beta=-2$ with $\gamma=0$ (the traditional inverse square law of distribution) and in Fig. 9, we show the first ten iterations. This shows how the line begins to spread out into a form that ultimately becomes circular and symmetric. In fact the ultimate spread which is symmetric within the 


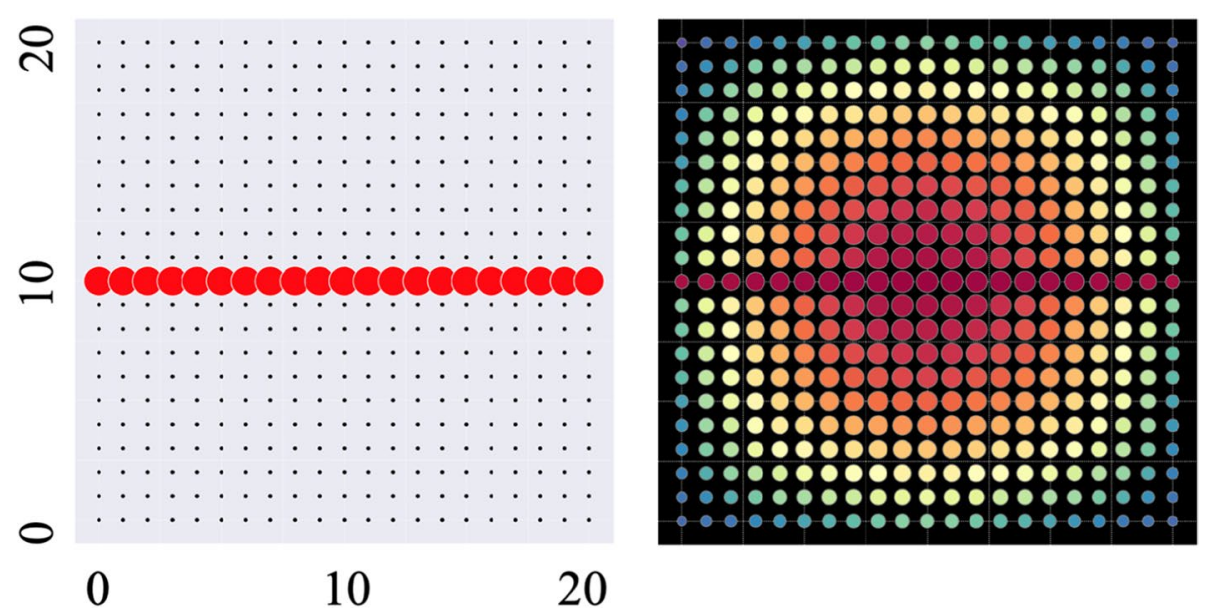

Fig. 8 Spreading the City and Scaling Population into the Two-Dimensional Space

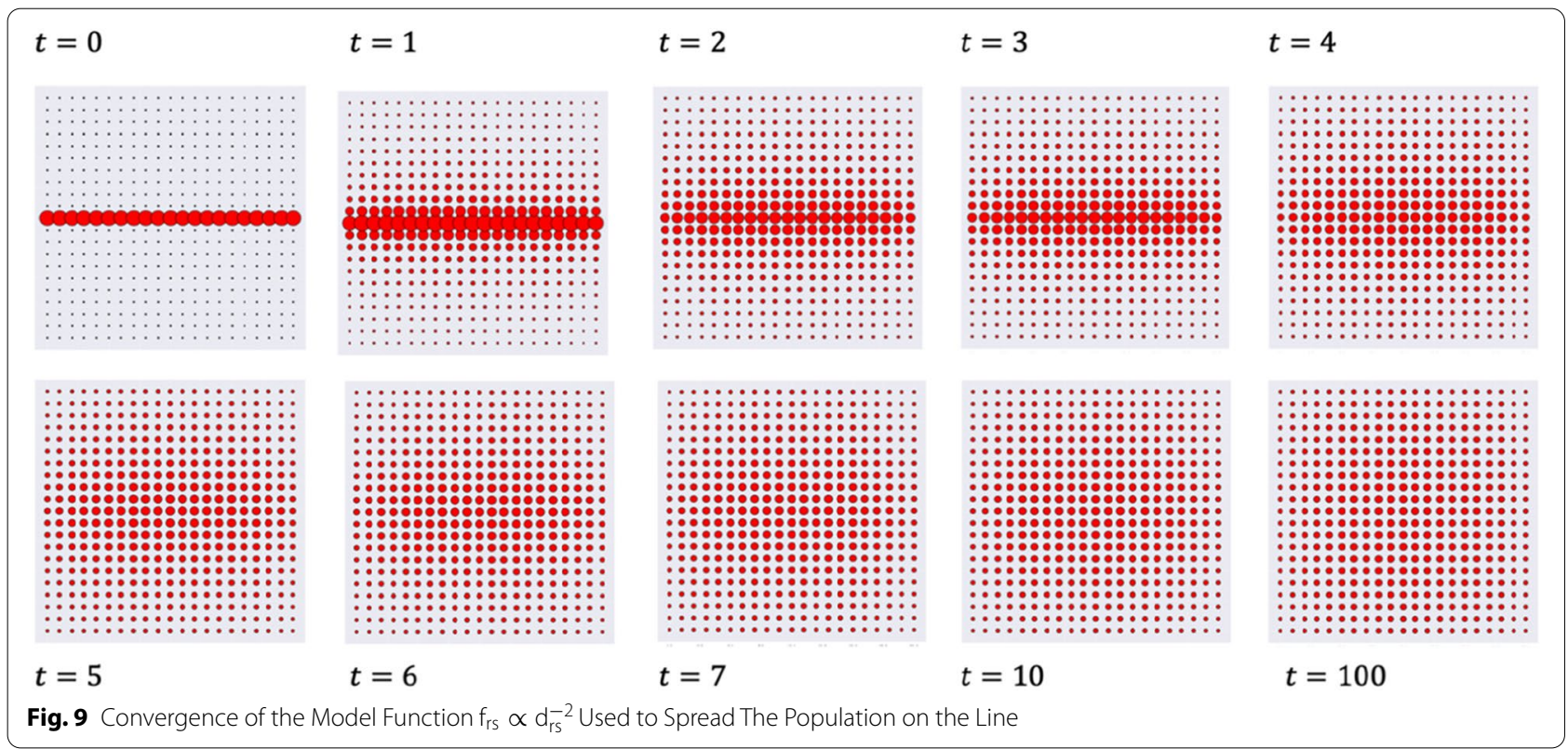

grid occurs quite rapidly which is close to the final outcome after 4 iterations and by the 20th is more or less unchanging although we have taken the number of iterations to the point where $t=100$.

We can now illustrate the nine possible solutions at $t=100$ defined by the limits of the parameters, set at all combinations of the values from $[\beta=-5, \beta=0, \beta=5]$ and $[\gamma=-1, \gamma=0, \gamma>1]$. The nine patterns are shown in Fig. 10 where we have arrayed them in 3 by 3 formation and this is a clear illustration of the effects of the centralising and decentralising forces that originate from everybody living on the line in the first instance.
6 Different initial configurations based on the line Although our focus here is on linear cities, we can use the logic of maximising local accessibilities to explore many different initial configurations and how their forms are transformed to a stable equilibrium. We will define three simple extensions here which consist of first adding another line which crosses the original line at the centre of the grid defining the overall city space. We then can add four locations in the middle of each of the four squares that define the quadrants of the cross and then we can complete this structure by adding population locations at the four extreme points defining the 


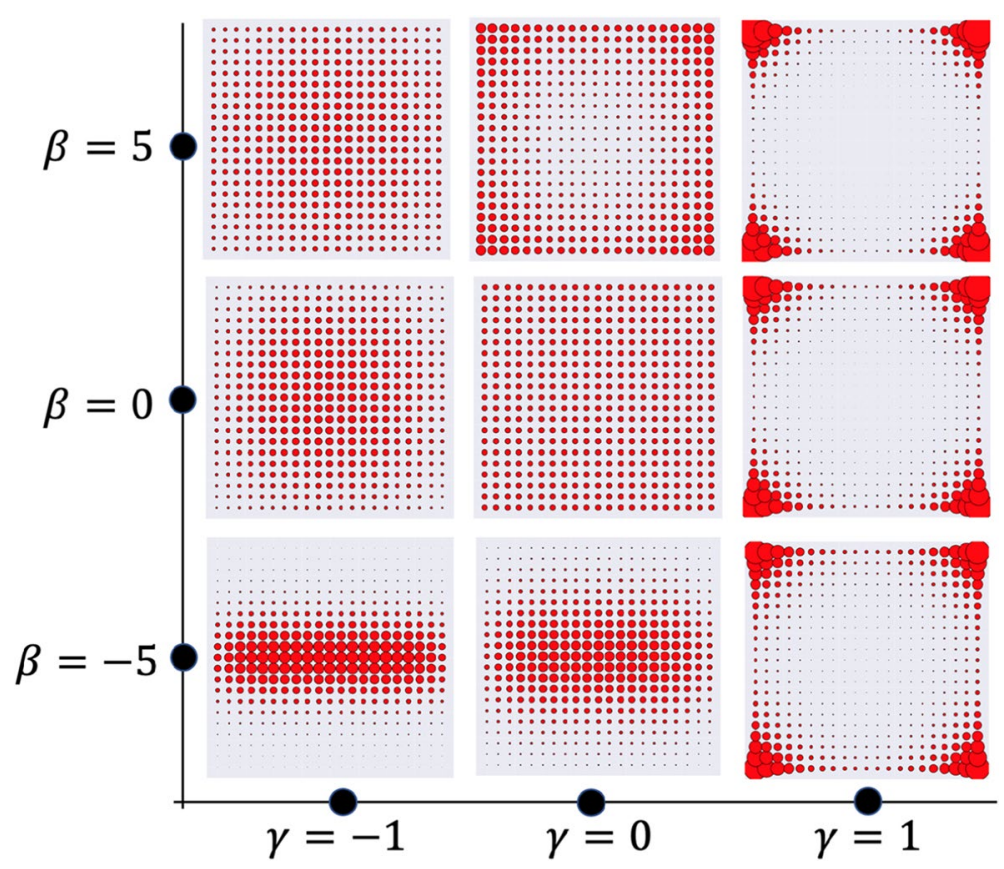

Fig. 10 The Limits of the Solution Space for Different Parameter Values of $d_{r s}^{\beta} \exp \left(\gamma d_{r s}\right)$

corners of the square grid. The first set of experiments involve using the standard inverse square model with $\beta=-2$ with $\gamma=0$ and iterating each of the three new configurations which we illustrate in the first column of Fig. 11. In this figure, we show each initial configuration from $t=0$ through the first iterations from $t=0,1$, $2,3, \ldots$ to the final iteration which marks a strong convergence where $t=300$.

From this figure, it is clear that the original form has little impact on the final configurations which all appear similar. In short, the original geometry is gradually ironed out, smoothed out if you like, from the initial city space. In fact we can compare this to the original configuration of the simplest line in Fig. 9 and the final outcome appears very similar to that shown above in Fig. 11. To an extent, this is a very obvious result in that the process of iteration to a new equilibrium is akin to a diffusion process where in the limit everything influences everything else and the original distribution is gradually lost from the picture. We have continued this iteration for many iterations and computed differences between each successive pattern. This does indeed converge very rapidly to a stable form but this form is not an even distribution across the space for the original geometry and the order of computation still make a difference to the ultimate form. To an extent, the limitation of this analysis is that we are not able to dimension any real time to this process for any process of change is much more lumpy, and thus likely to take a very long time to converge to a stable state.

We can also explore what happens when the parameters $\beta$ and $\gamma$ are varied across the range that we illustrated in Fig. 10. When the values of these parameters are positive and large, then the initial population will be rapidly diffused to the edge of the city space, defining a process of decentralisation. When these parameter values are negative and large, then this mirrors a process of centralisation but because the process in general is one of diffusion across the space from a dominant central location, the long term equilibrium still reflects the central location but this is smoothed out. We show these outcomes for the three different configurations in Fig. 12 where it is clear that the initial configurations make little difference to the long term structures and in comparison with the outcomes in Fig. 10, the decentralised patterns are pretty similar to one another whereas the centralised ones differ somewhat. There is much work still to do on exploring the actual equilibrium properties of these solutions.

We have computed many measures of spread and density for these different solutions and we will show these in a future extension of the ideas in this paper. The distributions of population can also be plotted and across this array of forms, we can detect some of these pertaining 

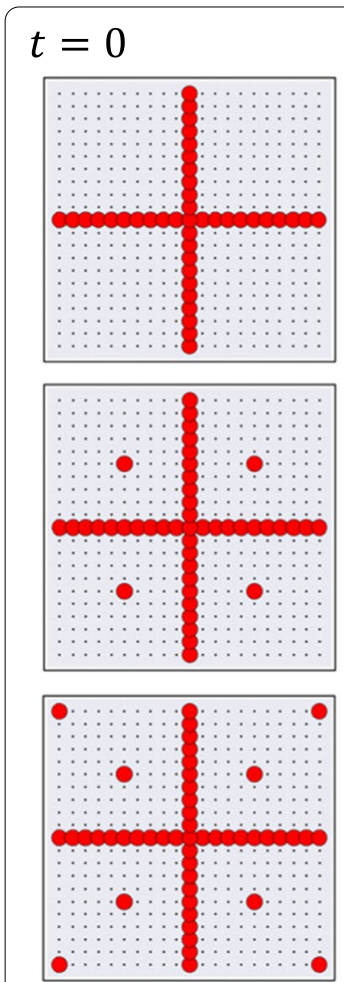

$t=1$
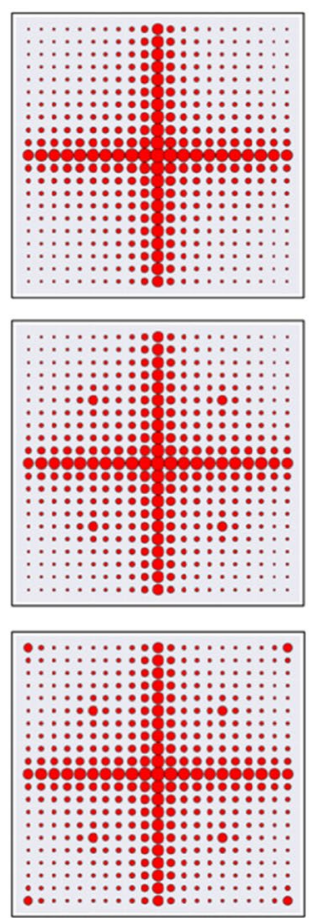

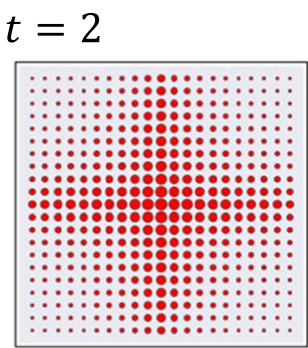

$t=3 \ldots$.
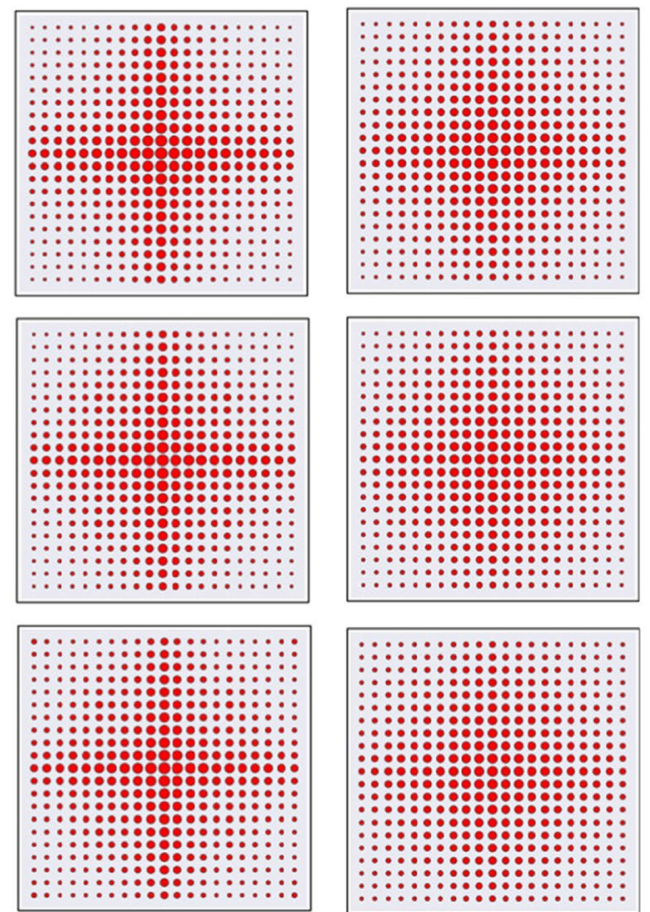
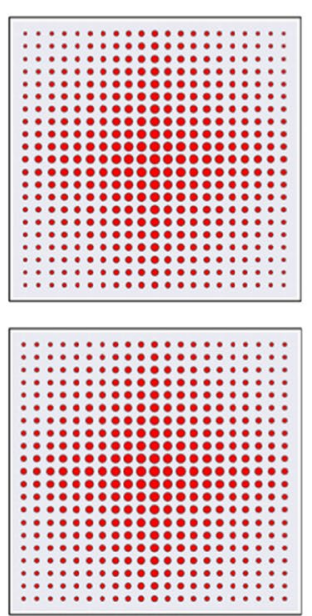
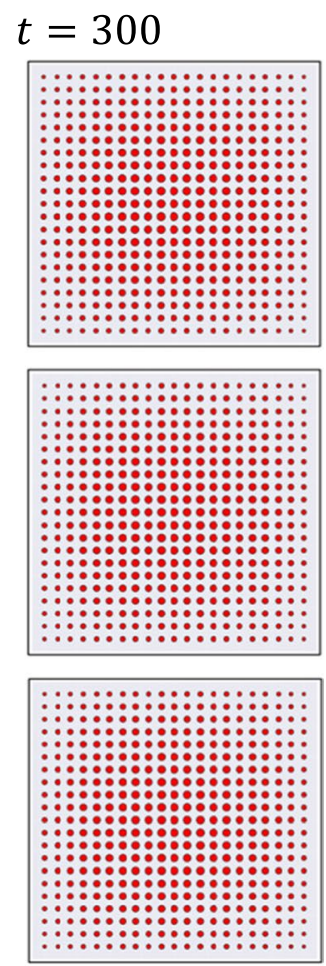

Fig. 11 The Convergence of Configurational Variants of the Linear City

to the frequencies of the size distributions we observe in real cities. This provides us with an additional filter that we can use to suggest which simulations are closer to real cities, and we also need to explore in much more detail the values of the parameters that influence the accessibilities and the trip patterns that lie behind these different forms. We have computed many of these already but with all work in progress, we have yet to report results.

\section{Conclusions: how real is this analysis?}

There have been many suggestions that the ideal city of the future should be linear in form so that accessibility to the countryside and to others spread out along the line can avail themselves of fast transportation. In fact, the linear city pays little regard to the total energy used and to questions of how fast transportation can be accessed. Moreover the sheer level of control required to implement such structures is likely to be almost impossible to achieve as and this is very clear from the fact that the idea has never resulted in truly linear cities continuing to exist in their original pristine form. As in Brasilia, La Cuidad Lineal, in Stalingrad and many more applications, once control is relaxed, these cities begin to grow and develop in more traditional ways based on messier, cluster-like radially concentric forms. The same fate probably awaits
Neom and although we have not specified a temporal dimension on how this city on a line might develop into a more concentric form, our illustrations in the previous sections do suggest that this might happen quite quickly. Once the line is established, populations could then begin to operate a market for land which would reinforce issues of agglomeration and accessibility spreading new growth in the city ultimately across the entire space.

In fact, prior to the first industrial revolutions, many smaller settlements where walking was the dominant mode of transportation complemented by horse drawn transport, were linear in form. This was particularly true of small villages. It took new transportation technologies to change this and in some respects, it might be argued that several of the proposals for future cities based on linear forms represents a flash back to an earlier age where transportation was of a different nature but also to an age when new transportation technologies emphasised the notion of travelling in a straight line. Only when one considers the behaviour of many individual agents all competing with each other for the most accessible space does the linear city idea appear to be inconsistent with present patterns of human movement behaviours. There is still much to be done on taking these ideas forward for the model we have proposed is highly unrealistic in 


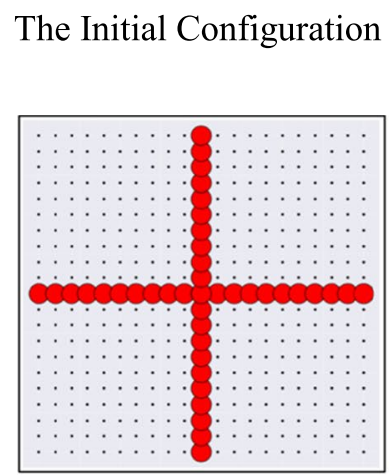

Centralisation $\beta=5$ and $\gamma=1$
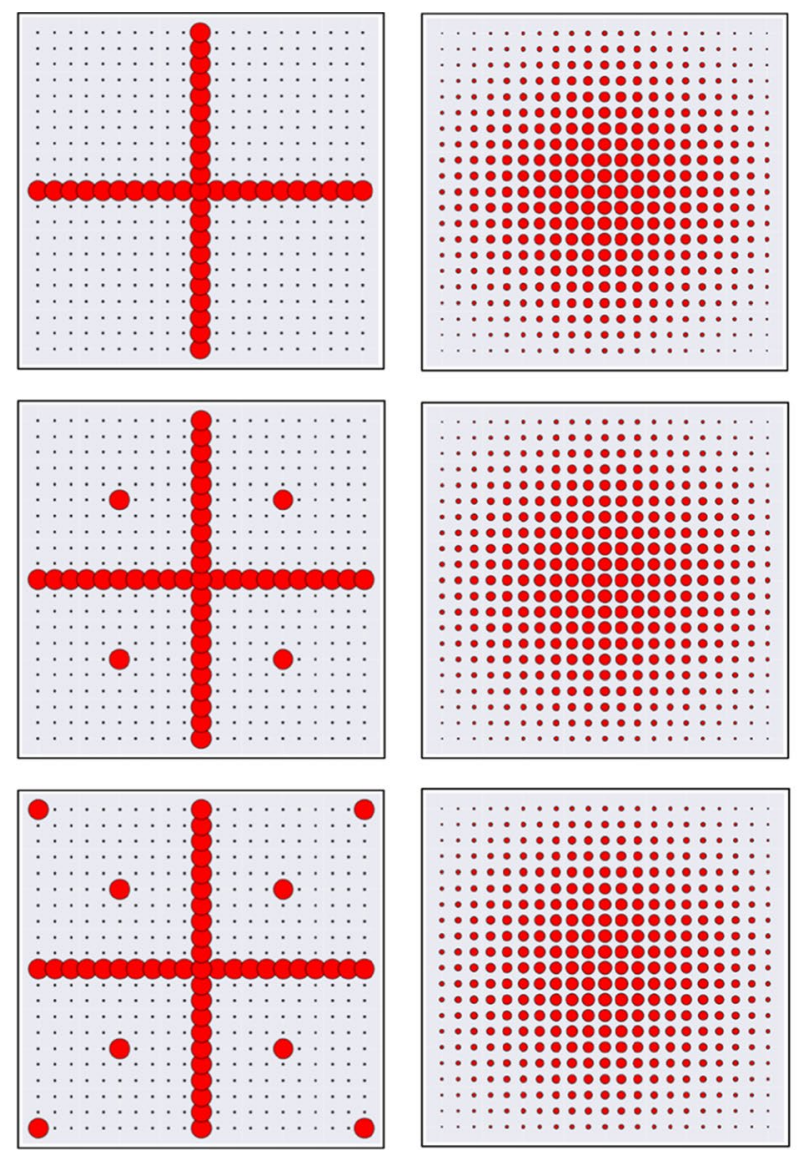
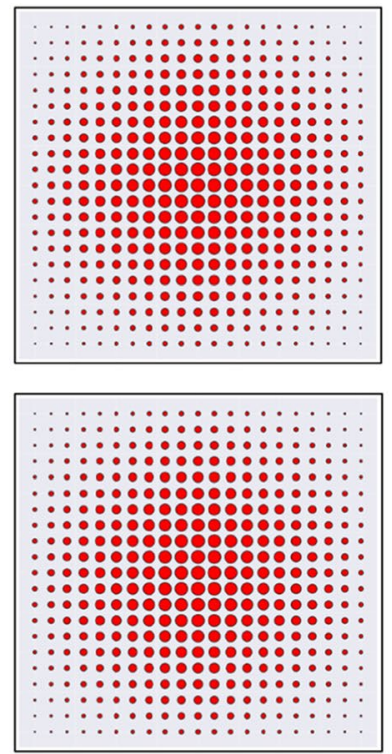

Decentralisation

$\beta=-5$ and $\gamma=-1$
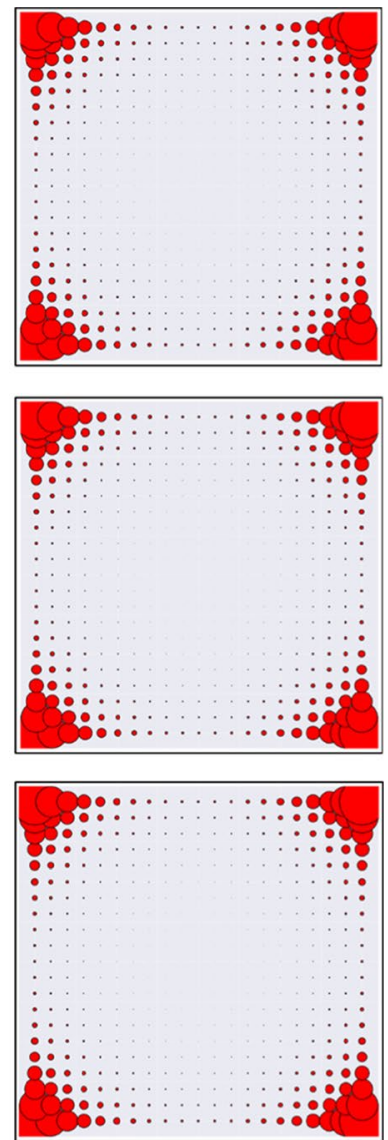

Fig. 12 Centralised \& Decentralised Equilibria for Three Elaborations on the Linear City

many respects and can certainly be improved. However we do not consider that the results of such extensions which involve adding much more richness and randomness would radically change the conclusions that we have come to here. In this sense, our conclusion is that the linear city will remain a fiction, a speculation, more a thought experiment than a potential reality, but something that is not without value in stretching our imaginations about possible urban futures. Even now in Neom, there is a proposal for building a virtual reality prior to anyone even living in the city, a digital twin that exists in the metaverse (Bell, 2021) on which one can experiment and explore the sorts of different futures that we have presented here.

\section{Acknowledgements}

There are no specific acknowledgements to other researchers.

\section{Author's contributions}

I am the sole author, wrote the paper, produced the research, wrote the computer programs and generated the graphics. The author read and approved the final manuscript.

\section{Funding}

This research is supported by The Alan Turing Institute under the QUANT2Contract-CID-3815811, and the UK Regions Digital Research Facility (UK RDRF) EP/M023583/1.

\section{Availability of data and materials}

All data is simulated within the model and does not need any copyright permissions.

\section{Declarations}

Competing interests

There are no competing interests.

Received: 7 February 2022 Accepted: 8 February 2022

Published online: 20 February 2022 


\section{References}

Antyufeev, A. V. \& Antyufeeva, O. A. (2019). Linear cities: Controversies, challenges and prospects. IOP Conference Series: Material Sciences and Engineering. 687, 1-6. doi:https://doi.org/10.1088/1757-899X/687/5/055025.

Banerji, R. (2012). Niemeyer's Brasilia: Does it work as a city? BBC world service. 7 December 2012. https://www.bbc.co.uk/news/magazine-20632277

Bell, J. (2021). Saudi's NEOM will have a digital twin in the 'Metaverse'. alArabiya news. https://english.alarabiya.net/News/gulf/2021/10/27/Saudis-NEOM-will-have-a-digital-twin-in-the-metaverse-FII

Boileau, I. (1959). La ciudad lineal: A critical study of the linear suburb of Madrid. The Town Planning Review., 30, 230-238.

Clarke, K. C. (2013). What is the world's oldest map? The Cartographic Journal., $50,136-143$.

Collins, G.R (1959) Linear planning throughout the world. Journal of the Society of Architectural Historians. 18, 74-93. Reprinted in Ekistics. 1960, 9, 242-25.

Doxiadis, C. A. (1967). On linear cities. The Town Planning Review., 38, 35-42.

Furundzic, D. S., \& Furundzic, B. S. (2013). Infrastructure corridor as linear city. University of Belgrade, Faculty of Architecture, Bulevar Kralja Aleksandra 73, Belgrade, Serbia.

Gold, J. R. (1995). The MARS plans for London, 1933-1942: Plurality and experimentation in the city plans of the early British modern movement. The Town Planning Review., 66, 243-267.

Gordon, A. (2021). Saudi Arabia resurrects discredited "linear city" concept in bigger, dumber form. Vice Media Group. https://www.vice.com/en/ article/m7a598/saudi-arabia-resurrects-discredited-linear-city-conce pt-in-bigger-dumber-form.

Hanson, I. A. (2020). Hyperloop transport technology assessment and system analysis. Transportation Planning and Technology., 43, 8803-8820.

Henderson, J. M., \& Quandt, R. E. (1958). Microeconomic theory: A mathematical approach. McGraw-Hill.

Hillier, W. J. (1996). Space is the machine. Cambridge University Press.

Hodder, I. (2005). Women and men at Çatalhöyük. Scientific American. Special Editions, 15, 34-41.

Jacobs, J. (1961). The death and life of great American cities. Random House.

March, L. (1967a). Let's build in lines. New Society. 20 July, 75-77.

March, L. (1967b). Homes beyond the fringe. Architects Journal. Royal Institute of British Architects, August, 334-337.

Marshall, S. (2005). Streets and patterns. Routledge.

Milyutin, N. A. (1930, 1975). Sotsgorod: The problem of building socialist cities. The MIT Press.

Page, S. E. (1999). On the emergence of cities. Journal of Urban Economics., 45, 184-208.

Solow, R. M., \& Vickery, W. S. (1971). Land use in a long narrow city. Journal of Economic Theory., 3, 430-447.

Tobler, W. R. (1970). A computer movie simulating urban growth in the Detroit region. Economic Geography, 46, 234-240.

Wang, P. (1993). Agglomeration in a linear city with heterogeneous households. Regional Science \& Urban Economics., 23, 291-306.

Wiebenson, D. (1960). Utopian aspects of Tony Garnier's "Cité Industrielle". Journal of the Society of Architectural Historians., 19, 16-24. https://doi.org/ 10.2307/987962

Worth, R. F. (2021). The dark reality behind Saudi Arabia's utopian dreams. New York Times. February 24, 2021. https://www.nytimes.com/2021/01/28/ magazine/saudi-arabia-neom-the-line.html

\section{Publisher's Note}

Springer Nature remains neutral with regard to jurisdictional claims in published maps and institutional affiliations. 